\title{
Water Governance in Cities: Current Trends and Future Challenges
}

\author{
Oriana Romano* and Aziza Akhmouch \\ Unit for Climate, Water, and SDGs, Cities, Urban Policies, and Sustainable Development Division, Centre for \\ Entrepreneurship, SMEs, Regions and Cities, Organisation for Economic Co-operation and Development, \\ 2 Rue André Pascal, 75775 Paris, France; aziza.akhmouch@oecd.org \\ * Correspondence: oriana.romano@oecd.org; Tel.: +33-145247686
}

Received: 19 December 2018; Accepted: 21 February 2019; Published: 10 March 2019

\begin{abstract}
Adapting water governance to changing needs, while coping with the uncertainties caused by climate change and the consequences of urbanisation and demographic growth, is key for inclusive, safe and resilient cities. The urgency of the challenges calls for innovative practices to enhance water security and provide better services to citizens, as foreseen by the Sustainable Development Goal (SDG) 6. The key question is: how to accomplish these objectives? While there is no doubt that technical solutions are available and play a fundamental role, they represent only part of the solution. Cities must ensure that the institutional frameworks in place are "fit to fix the pipes", from accessible information to adequate capacity, from sufficient funding to transparency and integrity, and from meaningful stakeholder engagement to coherence across sectoral policies. Building mainly on recent studies on water governance carried out by The Organisation for Economic Co-operation and Development (OECD) and specifically on urban water governance, this paper will discuss current trends and provide a set of tools for policy solutions based on OECD's 3Ps framework: people, policies and places. It will conclude by highlighting the importance of improving monitoring and evaluation for better design and implementation of urban water governance.
\end{abstract}

Keywords: water governance; infrastructure; urban water management; indicators; SDGs; stakeholder participation; water policy

\section{Water and Cities: A Challenging Future Ahead}

People's well-being and economic activities unquestionably hinge upon a critical component: water. In cities, water represents both an opportunity to carry out economic and social functions, and a threat, when consequences of disastrous events hit local economies and ecosystems. Yet, whether water is a challenge or an opportunity for cities largely depends on how well and efficiently it is governed. Indeed, urban water governance is about "doing things right" when managing too much, too little and too polluted water in cities and their hinterlands and providing adequate services.

Megatrends such as demographic growth, urbanisation and climate change increasingly affect water availability and quality in cities, where most people live and will be living in the future $(70 \%$ by 2050 [1]). By 2050, water demand will increase by 55\% compared to the year 2000, while four billion people will be living in water-stressed areas. Moreover, 240 million people will lack access to improved water sources, and almost 1.4 billion people are projected to lack access to basic sanitation [2]. In some rural and peri-urban areas of Mexico, Greece, Italy, and Portugal, amongst others, fractions of the population are not connected to water systems or have irregular access to water due to water scarcity [3].

Extreme water-related events are becoming increasingly frequent in cities all around the world. This is a challenge for over $80 \%$ of surveyed cities (Acapulco de Juarez, Amsterdam, Athens, 
Barcelona, Belo Horizonte, Bologna, Budapest, Calgary, Chihuahua, Cologne, Copenhagen, Culiacan, Daegu, Edinburgh, Glasgow, Grenoble, Hermosillo, Hong Kong, China; Kitakyushu, Krakow, Lisbon, Liverpool, Malaga, Marseille, Mexico City, Milano, Montreal, Nantes, Naples, New York City, Okayama, Oslo, Paris, Phoenix, Prague, Queretaro, Rio de Janeiro, Rome, San Luis Potosi, Singapore, Stockholm, Suzhou, Toluca, Turin, Tuxtla, Veracruz, Zaragoza and Zibo) from OECD and non-OECD countries [3]. Projections show that more people will be at risk from floods by 2050 (from 1.2 billion today to 1.6 billion), especially in coastal cities [2]. At the same time, cities are facing or are at high risk of drought. In 2015, in Brazil, for example, a country where 12\% of the world's freshwater resources are concentrated, Rio de Janeiro and São Paulo were hit by the worst drought in 84 years, while other areas in the country were experiencing flooding [4]. Moreover, these extreme events are incredibly costly: the severe flooding that hit Copenhagen in 2011 caused about EUR 700 million of damages; hurricane Sandy in New York City generated USD 19 billion of economic losses in 2012. In October 2018, hurricane Michael in Florida may have caused USD 25 billion in economic losses. Overall, between 2010 and 2050 the economic value of assets at risk of flood is projected to grow by $340 \%$, reaching USD 45 trillion [2].

Significant investment is required to renew and upgrade infrastructure. Investment in water supply and sanitation alone will require USD 6.7 trillion by 2050 and this bill could triple by 2030 if investment is extended to a wider range of water-related infrastructure [5]. For a total of $92 \%$ of surveyed cities obsolete or lacking infrastructure represents the most important challenge for the future of water management [3].

Current levels of service delivery and water security in OECD and emerging economies should not be taken for granted. Although cities in the OECD area can provide high quality water services, they cannot rely on current infrastructure and procedures to maintain acceptable levels of water supply and sanitation. Global agreements and frameworks, such as the 2030 Agenda for Sustainable Development, the Sendai Framework and the New Urban Agenda call upon cities to be better prepared for water-related disasters, and be more resilient and inclusive when providing water services. New socio-economic paradigms such as the circular economy are calling upon better use and re-use of natural resources, including water. The key question is how to accomplish these objectives? While technical solutions are well-known and available, they represent only part of the solution for cities to manage water in a sustainable, integrated and inclusive way, at an acceptable cost, and in a reasonable timeframe. Therefore, beyond determining "what-to-do", it is important to know "who does what", "at which level of government" and "how" [5]. In other words, it is essential to implement governance frameworks that can help cities to adapt to changing circumstances, while maintaining their central role in local, national and global contexts.

\section{Water Governance as a Means to an End}

Often water crises are water governance crises: managing water risks of too much, too little, and too polluted water is all the more challenging if the roles and responsibilities are not clearly allocated, stakeholders are not engaged, information is not shared and the capacities are not adequate to anticipate and tackle the risks [6].

The OECD (Organisation for Economic Co-operation and Development) defines water governance as "the set of administrative systems, with a core focus on formal institutions (laws, official policies) and informal institutions (power relations and practices) as well as organisational structures and their efficiency" [6] (p. 28). As such, governance is not synonymous with government, and is distinct from water management, which refers to operational activities, for instance delivery and recycling [6]. As a means to an end, governance is "good" if it can solve water challenges; it is "bad" if does not respond to place-based needs [5].

At urban level, three models of water governance can be distinguished [7]: Hierarchical, Market and Network governance. The hierarchical model relies on top-down approaches in decision-making and implementation for water supply and sanitation with centralised public authorities, vertical 
accountability and poor stakeholder engagement; the market model is based on a greater empowerment of stakeholders for water management and ownership of water assets. It began developing in the nineties through different forms (e.g., privatisation, corporatisation, contracts between private operators and municipalities). Finally, the network model builds on the co-operation of private, civil and public actors and decentralised management approaches [8]. Beyond the theoretical distinctions, in practice, governance models are hybrid. Market signals, public policies and collective action can reinforce each other in complex polycentric social systems, where actors at different scales adapt their rules over time according to the problems they are addressing [9]. In order to do so, a number of principles and requirements are important, including information provision (e.g., state of the environment, uncertainty and values); compliance with rules; institutional infrastructure (e.g., research, social capital, and rules), coordination across levels of government [10].

As a matter of fact, cities are unable to address the complexity of water challenges on their own, but need to work with lower and higher levels of governments [3] and put in place meaningful mechanisms for participation. "System thinking" can reduce institutional fragmentation, while improving co-ordination and coherence across different policies [11].

To provide better understanding and policy guidance on water governance to public, private and non-profit actors, the OECD together with member states and water experts gathered in the OECD Water Governance Initiative developed 12 Principles on Water Governance [5]. The Principles are structured around three pillars: effectiveness, efficiency, and trust and engagement. Governance should contribute to the definition and implementation of policy goals (effectiveness), at the lowest possible cost to society (efficiency), while ensuring inclusiveness of stakeholders (trust and engagement) (Figure 1).

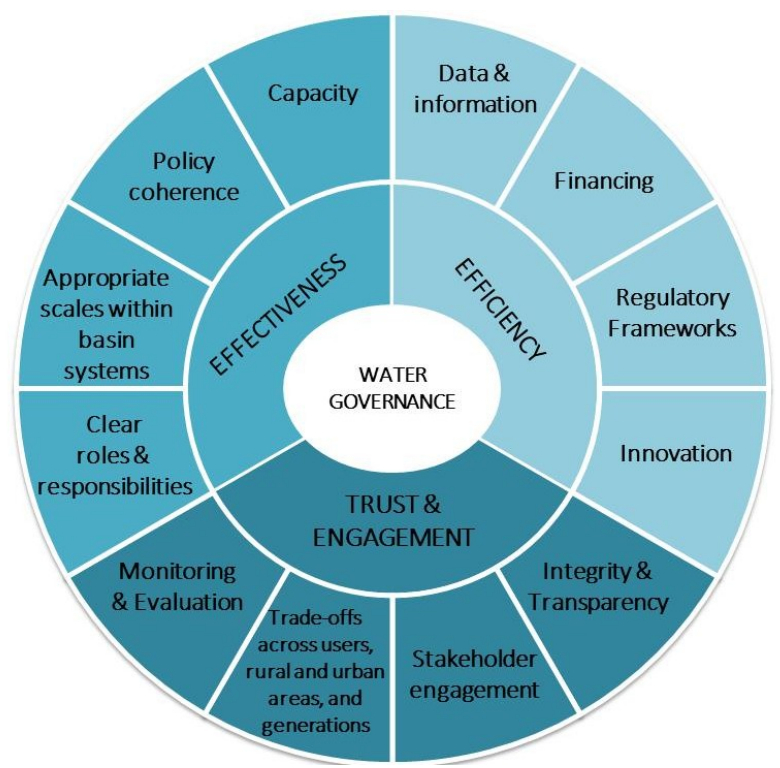

Figure 1. The Organisation for Economic Co-operation and Development (OECD) Principles on Water Governance. Source: OECD (2015), OECD Principles on Water Governance [5].

The 12 Principles refer to the water policy cycle, from the clear allocation of roles and responsibilities for water policy making, policy implementation, operational management and regulation (Principle 1) to regular monitoring and evaluation of water policy and governance (Principle 12).

\section{Water Governance in Cities}

In order to identify challenges and responses, the OECD employed an analytical framework that combined: (i) an assessment of the key factors affecting the effectiveness of urban water governance; 
(ii) a mapping of the roles and responsibilities at different levels of government; (iii) an appraisal of the main multi-level governance gaps to urban water management; and (iv) a focus on the policy responses to mitigate fragmentation and to foster integrated urban water management in cities and their hinterlands [3] (Figure 2).

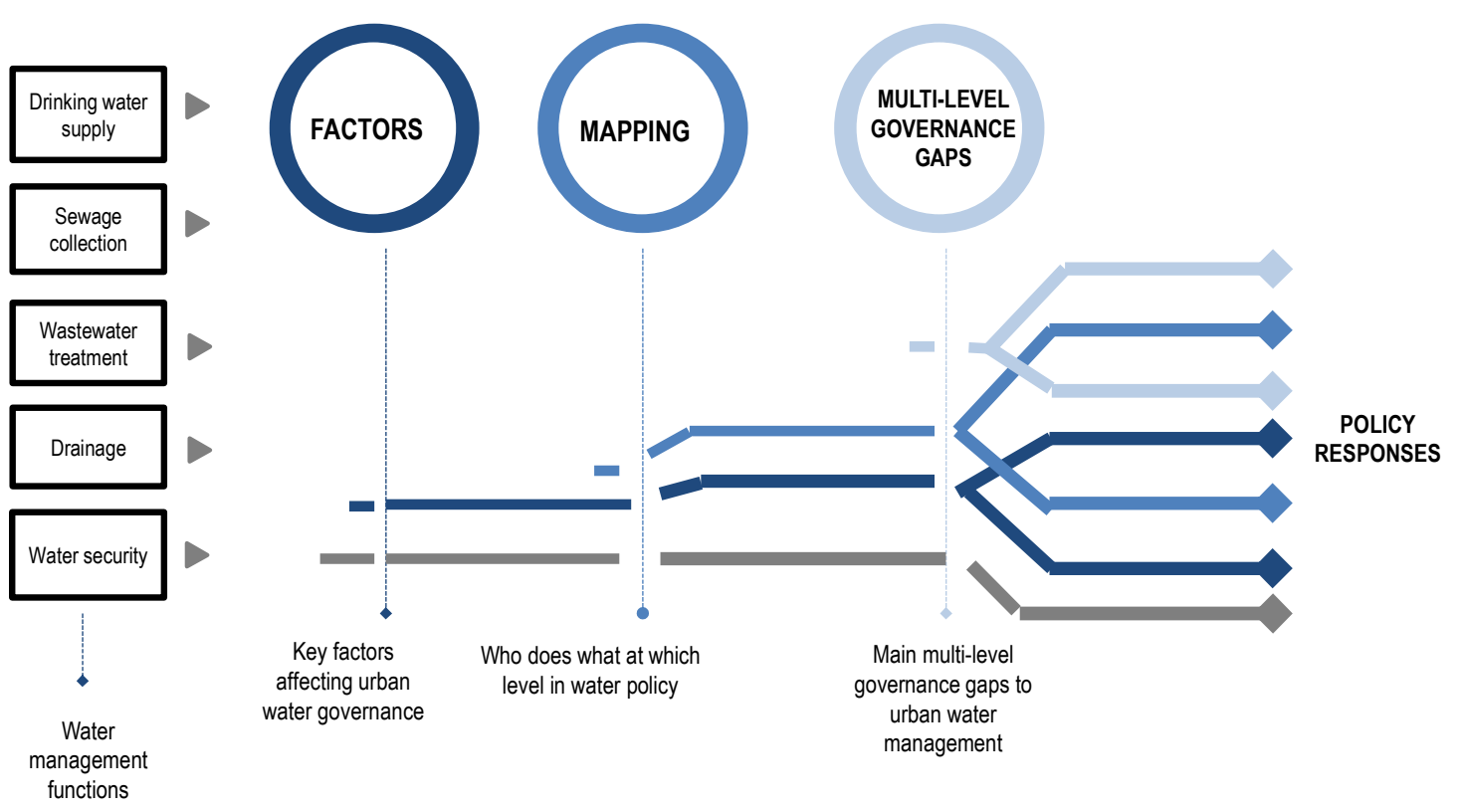

Figure 2. The analytical framework for assessing water governance in cities. Source: OECD (2016), Water Governance in Cities. OECD Publishing, Paris.

\subsection{Key Factors Affecting the Effectiveness of Urban Water Governance}

Several factors are shaping water governance in cities. According to the main results of the OECD survey carried out across 48 cities from OECD and non-OECD countries, water decisions in cities are affected by internal factors as well as by factors external to the water sector. The water sector is typically capital-intensive, requiring huge investment for infrastructure development and maintenance [12]. Water infrastructure is ageing, with negative impacts on efficiency and increasing operative costs due to leakages. This represents one of the greatest challenges for almost all surveyed cities (92\%). Cities like Liverpool, Lisbon and Zaragoza, amongst others, have heavily invested to reduce leakages and to rehabilitate the pipeline network. In Zaragoza, for example, water losses from the distribution network have been reduced by more than $40 \%$ over a period of ten years (1997-2007). However, beyond technical solutions, improving the information system, flow monitoring and the use of performance indicators related to water losses can help reduce both inefficiencies and environmentaland financial-related costs.

Institutional factors, external to the water sector, highly influence urban water governance. Amongst them, territorial reforms are affecting the water governance system in $52 \%$ of surveyed cities. For example, in terms of re-organisation of water services delivery, information sharing across actors initiating new horizontal and vertical interactions, stakeholder engagement, and policy complementarities across different sectors and between cities and surrounding areas are all crucial. This has been the case in France, where in 2015, the territorial reform (Nouvelle Organisation Territoriale de la République, NOTRe) had implications for the transfer of responsibilities on water and sanitation to communities of municipalities.

Inevitably, water governance is also affected by megatrends such as climate change and urban growth (79\% and $63 \%$ of surveyed cities, respectively [3]). Climate change is likely to increasingly affect the risks of "too much", "too little" or "too polluted" water. This can exacerbate the competition between water users. To cope with these challenges, cities would need to combine regulatory 
and economic instruments and to remove governance obstacles to long-term planning for climate change adaptation.

\subsection{Mapping of Roles and Responsibilities}

Urban water governance is a shared responsibility across different levels of government. While central governments have a prominent role in policy-making and regulatory functions, local governments have a more operative role in water functions, such as drinking water supply and drainage. Central governments tend to play an important role in water security policy-making and implementation and are also heavily involved in the regulation of water services [3]. In general, there is a trend towards the establishment of dedicated water regulatory bodies dealing with tariff regulation and performance monitoring, amongst other things. In general, this trend accompanies a reform of the water industry, which might imply a reorganisation of water provisions around fewer but bigger operators. For instance, this has occurred in Italy, Portugal, England and Wales, where regulators work with both national and sub-national actors [13].

In most cities surveyed in the 2016 OECD report [3], local governments (municipalities) are the primary sub-national authorities in charge of designing and/or implementing policies for drinking water supply and wastewater services. Metropolitan authorities may deal with water supply and sanitation. For example, the metropolitan area of Barcelona, which is formed by 36 municipalities, promotes integrated management of water supply and sanitation in the metropolitan area.

There are also a series of co-ordination mechanisms at vertical and horizontal levels to enhance water security: in Glasgow (United Kingdom) the Metropolitan Glasgow Strategic Drainage Partnership (MGSDP) is a collaborative venture between local authorities, the Scottish Environment Protection Agency (SEPA), Scottish Water, Scottish Enterprise, Clyde Gateway and Scottish Canals. The scope of its responsibilities includes flood reduction and improved water quality. In Italy, the authorities of the optimal territorial areas (Ambiti Territoriali Ottimali, ATO) ensure local stakeholder participation in order to manage water services in an integrated manner. The advantage of the coordination mechanisms is to gather several authorities and stakeholders for a concerted action towards greater water security and coherent water management, while avoiding overlaps and duplications. The accomplishment of expected results depends on internal and external circumstances, including political willingness.

\subsection{Multi-Level Governance Gaps to Urban Water Management}

Cities face several multi-level governance gaps. In particular, cities may suffer from unstable or insufficient revenues undermining effective implementation of water responsibilities. A total of $69 \%$ of surveyed cities in Reference [3] reported difficulties in raising tariffs for water services. At the same time, many cities have introduced affordability measures for low-income groups. They consist of using progressive social tariffs (e.g., Grenoble, Hermosillo, Lisbon); and implementing pro-poor policies (e.g., Budapest, Calgary, Hong Kong, China) and providing assistance to rural communities (e.g., Veracruz); grants for low-income families (e.g., Singapore); or social funds for people living in disadvantaged areas (e.g., Grenoble and Malaga).

Capacity is often the "Achilles' heel" of sub-national governments: many cities are facing technical and human resources gaps to efficiently manage water. The former relates to planning, quality information, monitoring and evaluation. The latter covers issues regarding staff, expertise and managerial capabilities. Water management in cities involves expertise from different fields and requires the capacity to respond to emergencies (such as in cases of water-related extreme events), to set up measures for disaster prevention, as well as to carry out ordinary duties, which must all be implemented in coherence with citizens' needs and in co-ordination with other policies and sectors. The cities involved in the OECD 2016 [3] survey reported the lack of staff and managerial competencies $(65 \%)$ as the main source of their capacity gap. 
Other multi-level governance gaps are the following: weak articulation between institutional, functional and hydrological boundaries, which can hinder integrated water management that would optimise the opportunity cost of investments and the efficient use of water (administrative gap); fragmentation of tasks and lack of strategic vision across water-related sectors (policy gap); lack of institutional incentives for co-operation and contradictions between legal and regulatory instruments at different levels of government (objective gap), as obstacles to long-term and co-ordinated urban water governance. Moreover, weak stakeholder engagement (accountability gap) also represents a challenge. Data production (e.g., on the state of environment) can be incomplete or collected irregularly (information gap).

\section{The “3Ps" Framework}

OECD (2016) developed the "3Ps" framework (policy, people and places) in response to the above challenges [3] (Figure 3):

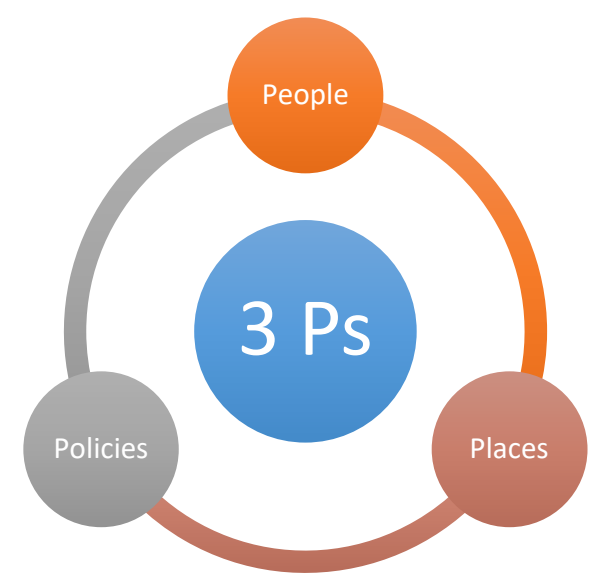

Figure 3. The "3Ps"Framework Source: OECD (2016), Water Governance in Cities. OECD Publishing, Paris.

Policy: Water governance has consequences for, and can be affected by a number of intrinsically related policies, such as land use, spatial planning, transport, energy, solid waste, environment, and agriculture, with impacts on water resource consumption, quality and security. Co-ordination across policies favours inter-sectoral complementarities while efficiently allocating resources. In the Netherlands, municipalities carry out "water assessments" to factor in water-related consequences and costs in spatial planning decisions. Building codes and housing regulation increasingly aim to reduce water consumption and to protect from water-related risks. In Germany, the City of Cologne co-ordinates water and spatial planning for new building areas to prevent flood damages from heavy rainfalls. Beyond planning and legal instruments, policy co-ordination can also take the form of financial incentives, as in the case of the City of Paris, which defined incentives for farmers to reduce their use of pesticides in order to protect water and natural resources.

People: A plethora of people from public, private, non-profit sectors to water users themselves have a stake or play a role in urban water management: urban planners, water service providers, regulators, advisors and civil society. They all contribute to dynamic and integrated approaches for water management. Stakeholder engagement can help build trust and ownership, secure willingness to pay for water services, ensure the accountability of city managers and service providers to end-users and citizens, set convergent objectives across policy areas and prevent and manage conflicts over water allocation [14]. Stakeholder engagement is important to raise awareness about current and future water risks and to build the social and political acceptability of reforms. For example, within the Local Urban Environment Adaptation Plan for a Resilient City (BLUE AP), the City of Bologna (Italy) engaged 150 stakeholders during a year of consultations to set climate change adaptation measures, 
including specific measures for water management to cope with water scarcity and floods. Overall, 70 project ideas and six pilot actions were presented.

Places: Water cuts across boundaries. As such, developing a place-based understanding is required to overcome territorial mismatches and to favour co-operation between cities and their surroundings (rural and watersheds). In this case, rural-urban partnerships represent win-win-win solutions benefiting cities, upstream and downstream communities and ecosystems. They consist in cross-sectoral and holistic sets of initiatives (e.g., within a wider package of environmental policy initiatives) or are focused on single objectives/projects (i.e., management of water resources) [15]. In Montreal, a multi-stakeholder committee helps improve the quality of discharged water in catchment areas; in New York City, contracts between the utility and watershed communities help preserve both water quality and the economic dynamism of the area.

\section{Ways Forward: Improving Water Governance in Cities}

Urban water governance is critical for managing water-related risks at an acceptable cost and in a proper time, so that the next generation does not inherit liabilities and costs. Clearly, there is no "one size fits all" solution. Moreover, cities have different capacities to respond to challenges. Correctly addressing these challenges requires assessing the range of political, institutional and administrative rules, practices and processes (formal and informal) through which decisions are taken and implemented. To support governments in this endeavour, the OECD together with experts from the public, private and non-for-profit sectors gathered within the OECD Water Governance Initiative, developed a Water Governance Indicator Framework that cities can use to identify whether water governance conditions are in place and function or need improvement [16]. The OECD Water Governance Indicator Framework is a self-assessment tool, which is part of the implementation strategy of the OECD Principles on Water Governance. The framework is composed of 36 indicators, measuring the what (policy framework), the who (institutions in charge) and the how (co-ordination tools for water policies) for each Principle. Differently from other measurement frameworks, the OECD Water Governance Indicator Framework can provide a global picture on the water governance system, rather than focusing on specific dimensions (e.g., transparency) or specific functions (e.g., water supply and sanitation). Information should be gathered through multi-stakeholder dialogues, which can lead to greater accountability of governments and stakeholders on how they share responsibilities and deliver the intended outcomes.

Cities can greatly benefit from the multi-stakeholder process to acquire information for each indicator. In fact, the self-assessment should be carried out in a participative manner in order to ensure that the process is transparent, neutral and open, as indicated by the 10-step methodology for self-assessment [16]. An open dialogue across stakeholders can inform policy makers in cities on the state-of-the-art of water governance and future expectations. This assessment in fact takes into account the diversity of opinions during the discussion. For each indicator, the assessment is complemented by the level of consensus amongst stakeholders. This is visually represented by water drops from 1 (low level of consensus) to 3 (high level of consensus) (Figure 4).

Identifying challenges is the first step towards effective responses for improved water governance in cities. Notably, cities will be increasingly facing challenges due to climate change and urbanisation, with consequences on competition for water resources between different users, on water quality and water security. However, cities are also laboratories for innovation, where experiments and pilots can take place. As such, fostering dialogue at a local level and building a consensus across a range of public authorities and stakeholders can help identify innovative, effective and efficient ways forward to better manage too much, too little and too polluted water now and in the future. 


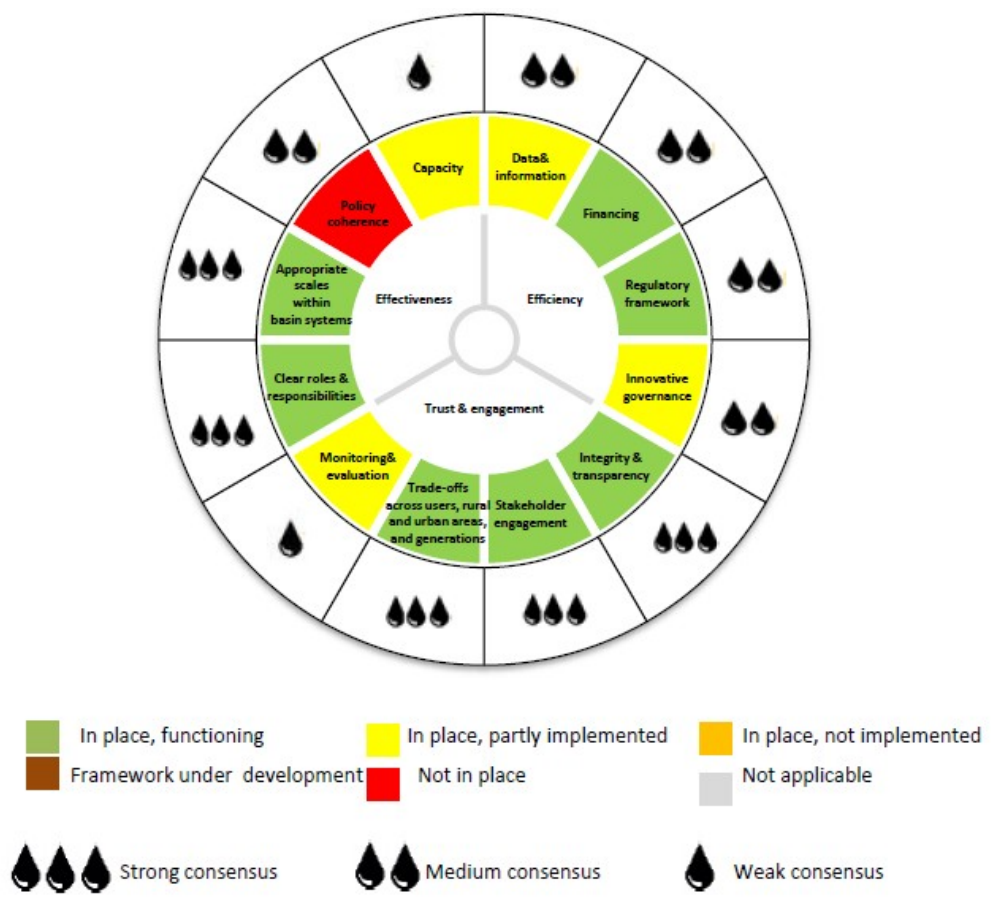

Figure 4. Visual representation of the Traffic Light System. Source: OECD (2018), Implementing the OECD Principles on Water Governance: indicator Framework and evolving practices, OECD Publishing.

Author Contributions: Conceptualization A.A. and writing-original draft preparation, review and editing, O.R.

Conflicts of Interest: The authors declare no conflict of interest.

\section{References}

1. UNDESA. Revision of World Population Prospects. Available online: www.un.org/development/desa/en/ news / population/2015-report.html (accessed on 21 February 2019).

2. OECD. OECD Environmental Outlook to 2050; OECD Publishing: Paris, France, 2012.

3. OECD. Water Governance in Cities, OECD Studies on Water; OECD Publishing: Paris, France, 2016.

4. OECD. Water Resources Governance in Brazil; OECD Publishing: Paris, France, 2015.

5. OECD. OECD Principles on Water Governance. OECD: Paris, France, 2015. Available online: www.oecd. org/governance/oecd-principles-on-water-governance.htm (accessed on 9 March 2019).

6. OECD. Water Governance in OECD Countries: A Multi-level Approach; OECD Publishing: Paris, France, 2011.

7. Van de Meene, S.J.; Brown, R.R.; Farrelly, M.A. 2011 Towards understanding governance for sustainable urban water management. Glob. Environ. Chang. 2011, 21, 1117-1127. [CrossRef]

8. Ostrom, E. Beyond markets and states: polycentric governance of complex economic systems. Am. Econ. Rev. 2010, 100, 641-672. [CrossRef]

9. Andersson, K.P.; Ostrom, E. Analyzing Decentralized Resource Regimes from a Polycentric Perspective. Policy Sci. 2008, 41, 71-93. [CrossRef]

10. Dietz, T.; Ostrom, E.; Stern, P.C. The Struggle to Govern the Commons. Science 2003, 302, 1907-1912. [CrossRef] [PubMed]

11. Tortajada, C. Water governance: Some critical issues. Int. J. Water Resour. Dev. 2010, 26, 297-307. [CrossRef]

12. Winpenny, J. Water: Fit to Finance? Catalyzing National Growth through Investment in Water Security, Report of the High Level Panel on Financing Infrastructure for a Water-Secure World. World Water Council: Marseille, 2015. Available online: http:/ / www.worldwatercouncil.org/sites/default/files/2017-10/WWC_ OECD_Water-fit-to-finance_Report.pdf (accessed on 9 March 2019).

13. OECD. The Governance of Water Regulators, OECD Studies on Water; OECD Publishing: Paris, France, 2015.

14. OECD. Stakeholder Engagement for Inclusive Water Governance; OECD Publishing: Paris, France, 2015. 
15. OECD. Rural-Urban Partnerships: An Integrated Approach to Economic Development, OECD Rural Policy Reviews; OECD Publishing: Paris, France, 2013.

16. OECD. Implementing the OECD Principles on Water Governance: Indicator Framework and Evolving Practices, OECD Studies on Water; OECD Publishing: Paris, France, 2018.

(C) 2019 by the authors. Licensee MDPI, Basel, Switzerland. This article is an open access article distributed under the terms and conditions of the Creative Commons Attribution (CC BY) license (http://creativecommons.org/licenses/by/4.0/). 